\title{
PERFORMANCE OF RECYCLED K10 MONTMORILLONITE CATALYST IN THE ALCOHOLYSIS OF EPOXIDISED PALM OLEIN
}

\author{
NORHAYATI MOHD NOOR*; HOONG SENG SOI*; TUAN NOOR MAZNEE TUAN ISMAIL*; \\ NURUL 'AIN HANZAH*; YEONG SHOOT KIAN" and ZAINAB IDRIS*
}

\begin{abstract}
The syntheses of palm-based polyols by the alcoholysis of epoxidised palm olein with isobutanol were carried out at $60^{\circ} \mathrm{C}$. The isobutanol to epoxidised palm olein molar ratio was fixed at 2.1:0.2. These reactions were catalysed by recycled $\mathrm{K} 10$ montmorillonite catalysts, which had undergone heat treatment at different temperatures, i.e., $50^{\circ} \mathrm{C}, 100^{\circ} \mathrm{C}, 150^{\circ} \mathrm{C}$ and $200^{\circ} \mathrm{C}$. The performance of the recycled $\mathrm{K} 10$ montmorillonite catalyst (untreated or treated) in the alcoholysis reaction and the role of acid sites content in the catalysts towards the alcoholysis reaction were investigated. Results had shown that all recycled and treated K10 montmorillonite had good catalytic effect on the alcoholysis reaction which produced palm-based polyols with similar properties when compared to fresh $\mathrm{K} 10$ montmorillonite catalyst. The highest acid sites content in the recycled $\mathrm{K} 10$ montmorillonite catalyst was obtained at $100^{\circ} \mathrm{C}$ heat treatment temperature. The high acid sites content in the catalyst had accelerated the alcoholysis reaction faster than the other recycled K10 montmorillonite catalysts. It can be concluded that K10 montmorillonite catalyst can be fully recycled in the alcoholysis of epoxidised palm olein with isobutanol, which may offer the potential to reduce the cost of polyol production.
\end{abstract}

Keywords: palm-based polyols, recycled K10 montmorillonite, epoxide ring-opening.

Date received: 21 August 2017; Sent for revision: 22 August 2017; Received in final form: 7 November 2017; Accepted: 2 February 2018.

\section{INTRODUCTION}

The preparation of polyols from renewable raw materials is highly desirable in order to reduce the dependency on petroleum-based raw materials. It provides sustainable and green solution to the demand for environmental-friendly polyols in the polyurethane industry (Argyropoulos et al., 2009; Zlatanic et al., 2002). Polyols from vegetable derivatives have been used in many commercial applications, including as components in polyurethane foams, elastomers and thermosetting

Malaysian Palm Oil Board,

6, Persiaran Institusi, Bandar Baru Bangi,

43000 Kajang, Selangor, Malaysia.

E-mail: norhayati.mohdnoor@mpob.gov.my plastics (Ang et al., 2014; Badri et al., 2001; Li et al., 2001; Lin et al., 2008). Much efforts with different methods have been carried out with the objective to effectively produce polyols with the desired properties (Arniza et al., 2015; Abraham, 2012; Narine et al., 2007; Norhayati et al., 2013; 2016a, b). One of the common methods to prepare polyols from vegetable oil is through the epoxidation and hydroxylation or alcoholysis of the epoxidised oils (Petrovic et al., 2002; Hazimah et al., 2011).

Oxirane ring in epoxidised oil can be opened by acids, hydrogen and alcohols. Carboxylic acid (i.e., acetic acid and formic acid) and inorganic acids (i.e., hydrogen bromide and hydrogen chloride) had been used as ring-opening agents. At room temperatures, polyols in the form of waxes were obtained when inorganic acid was used as ring-opening 
agent. Epoxidised oil which was ring opened with hydrogen in the presence of Raney nickel catalyst at the room temperature, had produced greasy polyols. Among these three ring-opening agents, alcohols showed the best performance where primary and secondary hydroxyl groups were created when using diols and monoalcohols, respectively ( $\mathrm{Li}$ et al., 2015). Generally, the alcoholysis reaction can be catalysed by acids or bases. However, it was reported that alcoholysis catalysed by base was successful only if the oil contains practically no free fatty acid (Siegfried et al., 2002). In the conventional method for producing oleochemical-based polyols, homogeneous catalysts were preferred for the alcoholysis reaction. Examples of homogeneous catalysts used were phosphoric acid, formic acid, acid-blocked version of $70 \%$ bis(dimethylaminoethyl) ether with 30\% dipropylene glycol (DABCO ${ }^{\circledR} \mathrm{BL}$ 17) manufactured by Evonik Nutrition \& Care, Germany, $\rho$-toluene sulphonic acid monohydrate ( $\rho$-TSA) and boron trifluoride-diethylether complex. Some of the disadvantages of homogeneous catalysts were high cost, high reactivity and non-recyclable. In many cases, when dealing with some of the homogeneous catalysts, a washing step was required to remove the chemical residues in the polyol obtained after the alcoholysis reaction (Hazimah et al., 2011; Lozada et al., 2009). There is a drawback associated with the washing step or polyol neutralisation, where a large amount of effluent and residues would be generated. Their disposal may cause environmental problems.

In this study, heterogeneous catalyst (K10 montmorillonite) was used in the alcoholysis reaction of epoxidised refined, bleached and deodorised (RBD) palm olein with isobutanol. K10 montmorillonite catalyst is a synthetic clay produced from natural montmorillonites and is available from many suppliers in large quantities. Usually, this catalyst can typically be recovered and recycled. The structure of K10 montmorillonite catalyst was studied by Nagendrappa (2002) (Figure 1). The chemical formula of $\mathrm{K} 10$ montmorillonite is $\mathrm{Al}_{2} \mathrm{Si}_{4} \mathrm{O}_{10}(\mathrm{OH})_{2} \cdot \mathrm{nH}_{2} \mathrm{O}$. The crystalline structure of $\mathrm{K} 10$ montmorillonite consists of multiple layers and each layer is made up of one octahedral alumina sheet sandwiched between two tetrahedral silica sheets. This clay contains both Brønsted and Lewis acidic catalytic sites which has the ion exchange function that allows it to work efficiently as a catalyst. Reactions catalysed by K10 montmorillonite were usually carried out under mild conditions with high yields and high selectivity (Kaur and Kishore, 2012).

Heat treatment was applied to the recycled K10 montmorillonite catalyst. It was reported that the quantity of water between the sheets had influence on the acidity of ion exchange in clays. When the clay was heated to around $100^{\circ} \mathrm{C}$, most of the interlamellar water was removed until only 'one layer' of water remained. At this stage, the Brønsted acidity increased to that of a very strong acid. By heating the clay to a higher temperature (at around $200^{\circ} \mathrm{C}-300^{\circ} \mathrm{C}$ ), it will make the clay interlayer structure collapse as the water is driven out. This will result in a decrease in Brønsted acidity and increase in Lewis acidity. By further heating the clay to around $450^{\circ} \mathrm{C}$ and above, a complete dehydroxylation of the aluminosilicate lattice occurred, producing a completely amorphous solid that retains Lewis acidity (Ballantine, 1995; Kaur and Kishore, 2012).

The alcoholysis of epoxide group can be promoted by clay catalyst and it was recognised as a selective catalyst for a wide range of organic transformations (Rios et al., 2005). Isobutanol ( $\beta$-branched alcohol) was used as an alcohol in this study. The presence of a branch in $\beta$ position introduces steric hindrance constraints in alcoholysis. The results with isobutanol could be extrapolated to linear and other $\beta$-branches primary alcohols (Rios et al., 2003). The reaction scheme of the alcoholysis of epoxidised RBD palm olein (EPOo) with isobutanol in the presence of catalyst (fresh K10, recycled K10 and treated recycled K10 montmorillonite) to produce palm-based polyol is shown in Figure 2. This article will highlight the performance of recycled K10 montmorillonite catalyst in the alcoholysis reaction of epoxidised RBD palm olein with isobutanol.

\section{MATERIALS AND METHODS}

\section{Materials}

K10 montmorillonite catalyst was purchased from Fluka-Chemica (Germany). It was used without further modification. The recycled K10 montmorillonite catalyst was collected from the alcoholysis process of EPOo with isobutanol at laboratory scale. EPOo was obtained from the Malaysian Palm Oil Board (MPOB) polyol pilot plant [specification: acid value $=0.4 \mathrm{mg} \mathrm{KOH} \mathrm{g}^{-1}$, iodine value $=0.8 \mathrm{~g} \mathrm{I}_{2} 100 \mathrm{~g}^{-1}$, oxirane oxygen content $=3.2 \%$, weight average molecular weight $\left(\mathrm{M}_{\mathrm{w}}\right)=1000-1100$ Daltons, viscosity at $25^{\circ} \mathrm{C}=127.0 \mathrm{mPa}$.s and $2.0 \mathrm{Y}$ 10.0R 1.0B of Lovibond colour]. Isobutanol and acetone of analytical reagent grade were purchased from Fisher Scientific (United Kingdom). EPOo and isobutanol were dried prior to alcoholysis. The moisture content of the dried EPOo and isobutanol were $0.04 \%$ and $0.08 \%$, respectively.

\section{Methods}

Catalyst preparation. After the first alcoholysis run, the K10 montmorillonite catalyst was filtered and collected. The collected recycled K10 


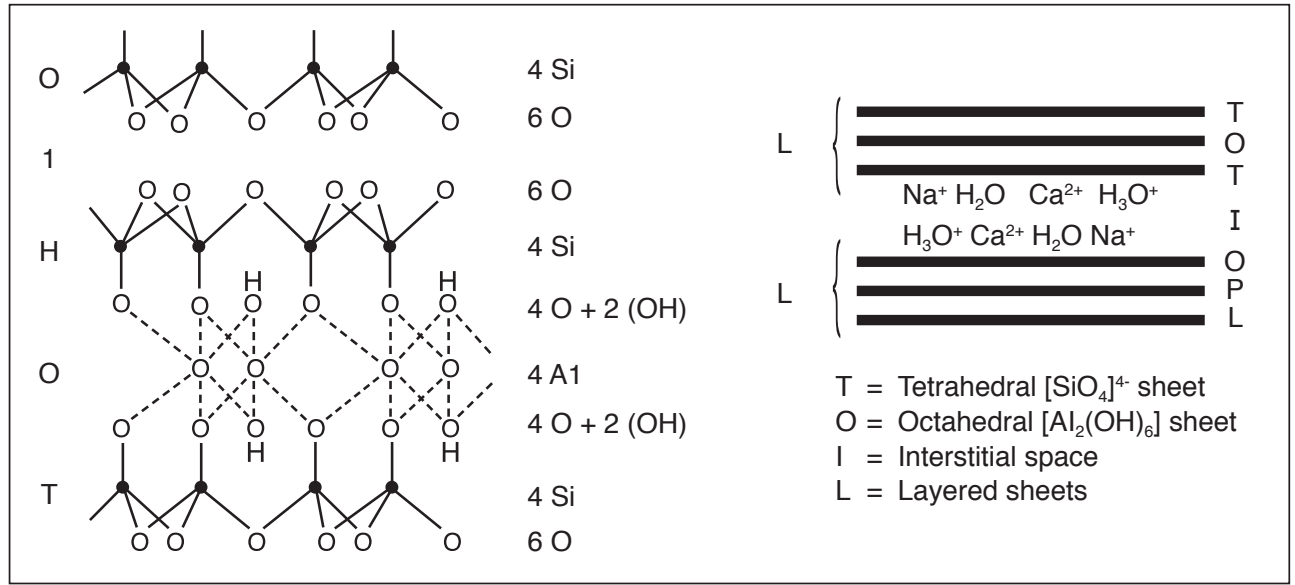

Figure 1. Chemical structure of K10 montmorillonite.<smiles>CCCCCCCCCCCCCCCC(=O)OCC(COC(=O)CCCCCCCC1OC1CCCCCCCC)OC(=O)CCCCCCCC1OC1CCCCCCCC</smiles><smiles>CCCCCCCCCC(O)C(CCCCCCCCC)OCC(C)C</smiles>

Idealised structure

Figure 2. Reaction scheme of alcoholysis of epoxidised refined, bleached and deodourised (RBD) palm olein (EPOo) with isobutanol to produce palm-based polyol. Catalyst $=$ fresh K10, recycled K10 and treated recycled K10 montmorillonite.

montmorillonite catalyst was divided into several portions for subsequent retreatments and reuse. The unwashed recycled K10 montmorillonite catalyst was used directly without any treatment. The purpose of washing and heat treatments was to remove impurities such as polyols which had covered the surface of the catalyst. The washed recycled K10 montmorillonite catalyst was prepared by mixing $200 \mathrm{~g}$ of collected recycled K10 montmorillonite catalyst with approximately $800 \mathrm{ml}$ of acetone in the closed flask for $3 \mathrm{hr}$ at room temperature $\left(23^{\circ} \mathrm{C}\right)$. Then, the solid catalyst was separated by using vacuum filtration (Whatman filter paper No. 5). The washed recycled K10 montmorillonite catalyst was dried at room temperature $\left(23^{\circ} \mathrm{C}\right)$. The washed K10 montmorillonite catalyst was subjected to heat treatment at different temperatures, i.e., $50^{\circ} \mathrm{C}, 100^{\circ} \mathrm{C}$, $150^{\circ} \mathrm{C}$ and $200^{\circ} \mathrm{C}$. The heat treatment was conducted for $2 \mathrm{hr}$ under air flow, with a heating rate of $20^{\circ} \mathrm{C}$ min $^{-1}$ using a Lenton Furnace. The colour of the washed recycled K10 montmorillonite catalyst (UC-W) was similar to the colour of the fresh K10 montmorillonite catalyst (FC). Description on treatments performance onto the catalysts and their appearances are shown in Table 1.

Catalytic reaction and purification of reaction products. The alcoholysis reaction was carried out in a $500 \mathrm{ml}$ reaction flask equipped with a thermometer. The flask was placed in an oil bath. A polytetrafluoroethylene (PTFE) coated stainless steel shaft, and an anchor flat propeller were used 


\begin{tabular}{|c|c|c|c|}
\hline Description of catalyst & $\begin{array}{c}\text { Appearance } \\
\text { of catalyst }\end{array}$ & $\begin{array}{l}\text { Description } \\
\text { of catalyst }\end{array}$ & $\begin{array}{c}\text { Appearance } \\
\text { of catalyst }\end{array}$ \\
\hline $\begin{array}{l}\text { Unwashed recycled K10 } \\
\text { (UC) }\end{array}$ & & $\begin{array}{l}\text { Washed and dried recycled } \\
\text { K10 at } 100^{\circ} \mathrm{C} \\
\text { (UC-100) }\end{array}$ & \\
\hline $\begin{array}{l}\text { Washed recycled K10 } \\
\qquad(\mathrm{UC}-\mathrm{W})\end{array}$ & & $\begin{array}{l}\text { Washed and dried recycled } \\
\mathrm{K} 10 \text { at } 150^{\circ} \mathrm{C} \\
\text { (UC-150) }\end{array}$ & \\
\hline $\begin{array}{l}\text { Washed and dried recycled } \\
\mathrm{K} 10 \text { at } 50^{\circ} \mathrm{C} \\
\text { (UC-50) }\end{array}$ & & $\begin{array}{l}\text { Washed and dried recycled } \\
\mathrm{K} 10 \text { at } 200^{\circ} \mathrm{C} \\
\text { (UC-200) }\end{array}$ & \\
\hline
\end{tabular}

Note: UC, UC-W, UC-50, UC-100, UC-150 and UC-200 are the denotation of catalysts. Heat treatment temperatures: $50^{\circ} \mathrm{C}$

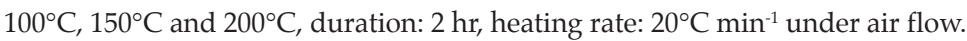

for stirring (approximately at $200 \mathrm{rpm}$ ). About $10 \mathrm{~g}$ of the prepared catalyst was pre-mixed with $154 \mathrm{~g}(2.1$ mol) of the dried isobutanol at $60^{\circ} \mathrm{C}$ for 15 min before the addition of $100 \mathrm{~g}(0.2 \mathrm{~mol})$ of the dried EPOo. The isobutanol was used in excess. The reaction was allowed to take place under continuous stirring. The reaction was stopped when the conversion of oxirane oxygen content (OOC) was $\geq 90 \%$. The obtained reaction product was cooled down to room temperature $\left(23^{\circ} \mathrm{C}\right)$.

In order to ease the separation of the catalyst from the reaction mixture, $100 \mathrm{ml}$ of acetone was added and stirred. The catalyst was separated from the reaction mixture via vacuum filtration using Whatman filter paper No. 5. Excess isobutanol and acetone were removed from the reaction product via distillation process. A $500 \mathrm{ml}$ of three-necked round bottom flask containing the filtered reaction mixture was placed in an oil bath, equipped with a condenser and a vacuum pump. A magnetic bar was used for stirring. Excess isobutanol and acetone were removed from the reaction product within 5 to $6 \mathrm{hr}$ at temperature of $115^{\circ} \mathrm{C}$ and at 80 mbar of vacuum pressure. Then, the reaction product obtained was dried at $115^{\circ} \mathrm{C}$ under vacuum ( 9 mbar). The moisture content of the reaction product was monitored during the drying process and was less than $0.05 \%$. The yield of the final product was $>90 \mathrm{wt} \%$ based on the mass of initial EPOo. The prepared palmbased polyols were designated as POL-UC, POLUC-W, POL-UC-50, POL-UC-100, POL-UC-150 and POL-UC-200, respectively, depending on the types of treatment conducted on the recycled K10 montmorillonite catalysts as shown in Table 1. The PB-Isob was the palm-based polyol which was prepared using the method described above and fresh $\mathrm{K} 10$ montmorillonite as the catalyst.
Yield > 90 wt\%; FTIR (film) $/ \mathrm{cm}^{-1}: 3472,2923$, 2853 and 1743; ${ }^{1} \mathrm{H}$ NMR $\left(\mathrm{CDCl}_{3}, 500 \mathrm{MHz}\right): \delta 5.10$ (s, $\mathrm{H}, \mathrm{CHO}), 4.14-3.97\left(\mathrm{~m}, 4 \mathrm{H}, \mathrm{CH}_{2} \mathrm{O}\right), 3.32(\mathrm{~m}, \mathrm{H}$, $\mathrm{CHOH}), 3.19-3.02\left(\mathrm{~m}, 2 \mathrm{H}, \mathrm{CH}_{2} \mathrm{O}\right), 2.91(\mathrm{~m}, \mathrm{H}, \mathrm{CHO})$, $2.16-2.13\left(\mathrm{t}, J=7.5 \mathrm{~Hz}, 6 \mathrm{H}, \mathrm{CH}_{2} \mathrm{COOR}\right), 1.70-1.65(\mathrm{~m}$, $\left.1 \mathrm{H}, \mathrm{CH}\left(\mathrm{CH}_{3}\right)_{2}\right), 1.50-1.42\left(\mathrm{~m}, 6 \mathrm{H}, \mathrm{CH}_{2} \mathrm{CH}_{2} \mathrm{COOR}\right)$, $1.32-1.10\left(\mathrm{~m}, 70 \mathrm{H}, \mathrm{CH}_{2}\right), 0.78-0.71\left(\mathrm{~m}, 15 \mathrm{H}, \mathrm{CH}_{3}\right)$; ${ }^{13} \mathrm{C} \mathrm{NMR}\left(\mathrm{CDCl}_{3}, 500 \mathrm{MHz}\right): \delta 173.0-172.5(\mathrm{ROC}=\mathrm{O})$, $82.4(\mathrm{COH}), 77.2(-\mathrm{CO}-), 72.4(\mathrm{COH}), 68.8(\mathrm{HCO})$, $61.8\left(\mathrm{H}_{2} \mathrm{C}-\mathrm{O}\right), 33.9\left(\mathrm{H}_{2} \mathrm{CC}=\mathrm{O}\right), 31.7-28.9\left(\mathrm{CH}_{2} \mathrm{CH}_{2}\right)$, $24.6\left(\mathrm{O}=\mathrm{CCH}_{2} \mathrm{CH}_{2}\right), 22.5\left(\mathrm{CH}_{2} \mathrm{CH}_{3}\right), 19.2\left(\mathrm{CHCH}_{3}\right)$, $13.9\left(\mathrm{CH}_{2} \mathrm{CH}_{3}\right)$.

Characterisation of catalyst and palm-based polyols. The Fourier transform infrared (FTIR) spectra of the catalysts were recorded between 4000 and $450 \mathrm{~cm}^{-1}$ wavenumber using a Nicolet MagnaIR 550 spectrometer series II, using 64 scans with a resolution of $6 \mathrm{~cm}^{-1}$. Samples were prepared by grinding with potassium bromide $(\mathrm{KBr})$ powder and pressing into a disc prior to analysis. The acidity of the catalysts was performed by temperature programmed desorption using ammonia (TPD$\mathrm{NH}_{3}$ ) as a probe molecule. The TPD- $\mathrm{NH}_{3}$ measurements were performed on a Thermo Finnigan TPDRO 1100 apparatus equipped with a thermal conductivity detector. Approximately $0.05 \mathrm{~g}$ of catalyst was placed in a reactor treated under $150^{\circ} \mathrm{C}$ for $15 \mathrm{~min}$ in nitrogen $\left(\mathrm{N}_{2}\right)$ at a flow rate of $30 \mathrm{ml} \mathrm{min}{ }^{-1}$ and $\mathrm{NH}_{3}$ in helium gas was ramped at a heating rate of $1^{\circ} \mathrm{C} \mathrm{min}{ }^{-1}$ for $60 \mathrm{~min}$. At room temperature, $\mathrm{N}_{2}$ was purged for $45 \mathrm{~min}$ to remove $\mathrm{NH}_{3}$ in the gas phase. The analysis of $\mathrm{NH}_{3}$ desorption was then carried out between $50^{\circ} \mathrm{C}$ and $900^{\circ} \mathrm{C}$ under a helium flow rate at 20 $\mathrm{ml} \mathrm{min}{ }^{-1}$ and at a heating rate of $10^{\circ} \mathrm{C} \mathrm{min}^{-1}$, and detected by a thermal conductivity detector. 
The viscosity of palm-based polyol was determined using a Brookfield Digital Rheometer, Model DV-III +. The colours of the EPOo and palmbased polyols were determined using Lovibond Tintometer Model F. Samples were analysed by heating the samples at $60^{\circ} \mathrm{C}$. Then, the samples were poured into the sample cell $(13.335 \mathrm{~cm})$ before measuring the colour. FTIR spectra of palmbased polyols were recorded using a Perkin Elmer FTIR Spectrum 100 Mild DTIR in the $4000-650$ $\mathrm{cm}^{-1}$ wavenumber range. The molecular weight distributions of palm-based polyols were measured using a Varian PL-gel permeation chromatography (GPC) 50 Plus equipped with a differential refractive index (DRI)/viscometer (combined detector). Tetrahydrofuran (THF) stabilised with $250 \mathrm{ppm}$ butylated hydroxytoluene (BHT) was used as the eluent and the flow rate was fixed at $1.00 \mathrm{ml} \mathrm{min}^{-1}$. The molecular weights of samples were analysed using a PLGel Mixed D column. The molecular weight distributions were obtained based on a calibration curve generated from polystyrene (PS) standards (Tay and Nurul, 2012). The moisture content of palm-based polyol was measured by using C30 Karl Fisher coulometer with Hydranal Coulomat-AG as an anolyte. The ${ }^{1} \mathrm{H}$ NMR and ${ }^{13} \mathrm{C}$ NMR of palm-based polyols were recorded on $500 \mathrm{MHz}$ JEOL JNM-ECX 500 spectrometers with chloroform $\left(\mathrm{CDCI}_{3}\right)$ as a solvent at room temperature. The oxirane oxygen content (OOC) of the reaction mixture and palm-based polyols were determined following the American Oil Chemists
Society (AOCS) Official Method Cd 9-57. The hydroxyl value (OHV) and the iodine value (IV) were determined according to the AOCS Official Methods Cd 13-60 (pyridine-acetic anhydride titration method) and Cd 1d-92 (cyclohexane-acetic acid titration method), respectively. The acid value (AV) was analysed according to AOCS Official Method Te 2a-64 (AOCS, 2007).

\section{RESULTS AND DISCUSSION}

\section{Characterisation of Catalyst}

FTIR spectra were used to identify the presence of functional groups and the structural characteristics in the catalyst samples. The FTIR spectra of fresh K10, recycled K10 and treated recycled $\mathrm{K} 10$ montmorillonite catalysts are shown in Figure 3. Catalysts of UC-50, UC-100, UC-150 and UC-200 shared similar FTIR spectra. The patterns of absorption features of these catalysts were largely unchanged after heat treatment at different temperatures.

Absorption peaks at around 3430 and 3625 $\mathrm{cm}^{-1}$ were attributed to stretching vibration of the hydroxyl groups and bending vibration was recorded at $915 \mathrm{~cm}^{-1}$. The band at $1640 \mathrm{~cm}^{-1}$ was due to the hydroxyl deformation of interlayer water in the catalysts. The broad bands at about 1041 and $1095 \mathrm{~cm}^{-1}$ correspond to the stretching vibration of the Si-O bond. The bands at 467 and $520 \mathrm{~cm}^{-1}$ are

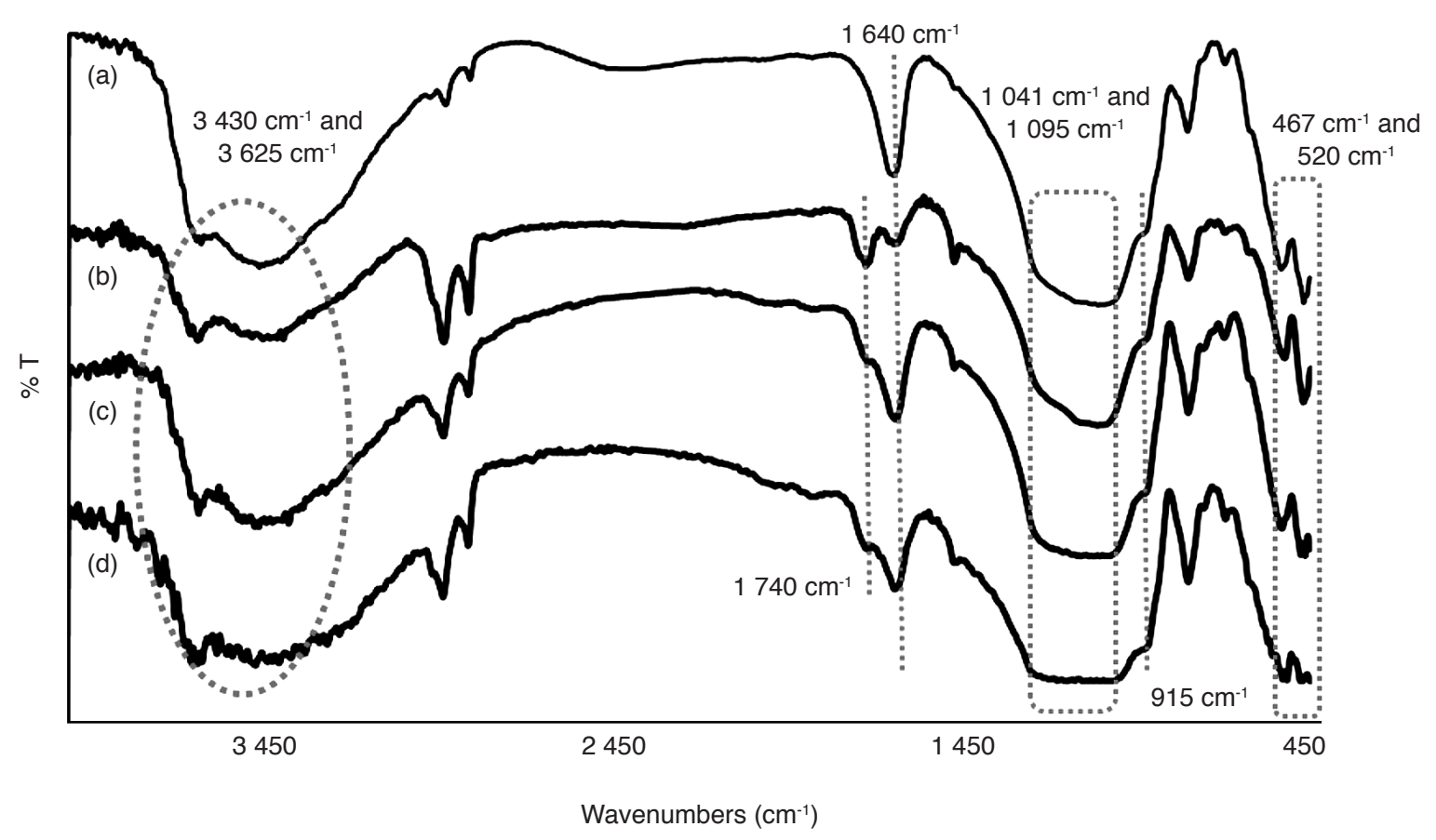

Figure 3. Fourier transform infrared (FTIR) spectra of (a) fresh K10 (FC), (b) recycled K10 (UC), (c) washed recycled K10 (UC-W) and (d) washed and dried recycled K10 montmorillonite catalysts (UC-50 to UC-200). 
attributed to the bending vibrations of Si-O-Al and stretching vibrations, respectively (Madejová, 2003; Tong et al., 2013). The band at $1740 \mathrm{~cm}^{-1}$ corresponds to the ester group from the palm-based polyol (Norhayati et al., 2013). The intensity of the ester peak was high in UC spectra and became low in the UC-W and UC-50 to UC-200 spectra. Logically, the unwashed recycled K10 will contain the trace of polyol component. The washing process will diminish some of the polyol traces which remained in the recycled $\mathrm{K} 10$ montmorillonite catalyst.

As the alcoholysis reaction was catalysed by acid sites, the total acidity of catalysts was determined by $\mathrm{NH}_{3}$-TPD. The acidic sites of fresh K10, recycled K10 and treated recycled $\mathrm{K} 10$ montmorillonite catalysts are shown in Table 2.

\section{TABLE 2. TOTAL ACIDIC SITES OF THE CATALYSTS}

\begin{tabular}{cc}
\hline Catalysts & Acid sites $\left(\mathbf{m m o l ~ g}^{-1}\right)$ \\
\hline FC & 44.30 \\
UC & 2.19 \\
UC-W & 2.96 \\
UC-50 & 2.43 \\
UC-100 & 5.84 \\
UC-150 & 2.00 \\
UC-200 & 1.89 \\
\hline
\end{tabular}

Note: FC - fresh K10, UC - recycled K10, UC-W - washed recycled $\mathrm{K} 10$, UC-50 - washed and dried recylced $\mathrm{K} 10$ at $50^{\circ} \mathrm{C}, \mathrm{UC}-100$ washed and dried recycled $\mathrm{K} 10$ at $100^{\circ} \mathrm{C}$, UC-150 - washed and dried recycled $\mathrm{K} 10$ at $150^{\circ} \mathrm{C}$, UC-200 - washed and dried recycled $\mathrm{K} 10$ at $200^{\circ} \mathrm{C}$. Condition: Analysis of $\mathrm{NH}_{3}$ desorption was carried out at temperature $50^{\circ} \mathrm{C}-900^{\circ} \mathrm{C}$, under helium flow $\left(10^{\circ} \mathrm{C} \mathrm{min}^{-1}\right.$, $20 \mathrm{ml} \mathrm{min} \mathrm{m}^{-1}$.
According to the data obtained from $\mathrm{NH}_{3}-\mathrm{TPD}$ profile of the catalysts, the total acidic sites on surface of fresh K10 catalyst has been found to be around $44.30 \mathrm{mmol} \mathrm{g}^{-1}$. The acidic sites of the K10 catalyst was reduced to $2.19 \mathrm{mmol} \mathrm{g}^{-1}$ after being used in the alcoholysis reaction. The acidic site of recycled K10 catalyst was improved after washing with acetone, i.e., $2.96 \mathrm{mmol} \mathrm{g}^{-1}$. Acetone had dissolved some of the traces of the polyol that covered the catalyst surface.

The acidity of ion-exchanged clays is very much influenced by the quantity of water located between the layered sheets in the clay. In this study, when the recycled $\mathrm{K} 10$ catalyst was heated to around $100^{\circ} \mathrm{C}$, most of the interlamellar water was removed until only 'one layer' of water remained. It caused a markedly increase of Brønsted acidity to that of a very strong acid, shown by the amount of UC-100 catalyst acidic sites, i.e., $5.84 \mathrm{mmol} \mathrm{g}^{-1}$. By heating a clay to a higher temperature (at around $200^{\circ} \mathrm{C}-300^{\circ} \mathrm{C}$ ), the clay interlayer structure collapsed as the water was driven out, resulting in a decrease of Brønsted acidity (Ballantine, 1995; Kaur et al., 2012). This phenomenon was made evidence by the decreased of acidic sites in UC-200 catalyst, i.e., 1.89 mmol g-1.

\section{Effect of Catalysts on Palm-based Polyols Properties}

The changes of OOC of the reaction mixture during the alcoholysis reactions are shown in Figure

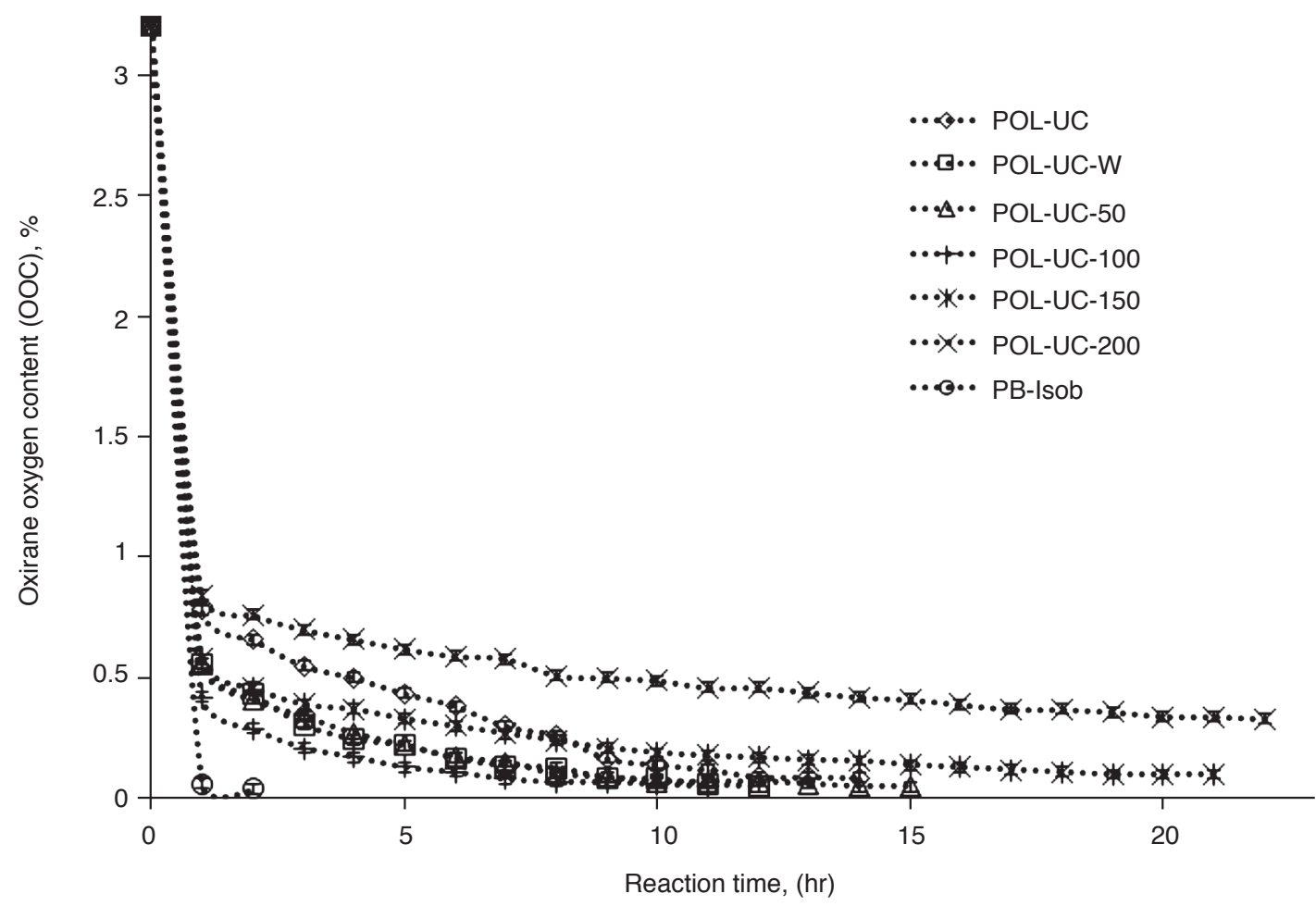

Figure 4. Changes in oxirane oxygen content (OOC) of reaction mixtures during alcoholysis reactions. 
4. Based on the experiments conducted, it was observed that fresh $\mathrm{K} 10$ montmorillonite catalyst (with the highest acid site, i.e., $44.30 \mathrm{mmol} \mathrm{g}^{-1}$ ) was able to promote the alcoholysis reaction, leading to the lowest OOC, i.e., $0.04 \%$, within $2 \mathrm{hr}$ of reaction time. The UC-100 catalyst showed the fastest catalytic effect in alcoholysis reaction compared to UC catalyst and other treated UC catalysts. This result was supported by Ballantine (1995) and, Kaur and Kishore (2012), where the Brønsted acid in clay (dried at $100^{\circ} \mathrm{C}$ ) was at the highest level of reactivity which contributed to the fast reaction. The catalytic effects of the catalysts during alcoholysis corresponded well with their respective number of acid sites content (Table 2). It was observed that the OOC was drastically reduced (to below than $1 \%$ ) after $1 \mathrm{hr}$ of reaction time and gradually decreased as the reaction progressed. In addition, longer reaction time (more than $10 \mathrm{hr}$ ) was required when using recycled K10 and treated recycled K10 catalyst in alcoholysis reaction as compared to fresh K10 montmorillonite catalyst due to lower number of acid sites of the recycled catalysts.

EPOo and prepared palm-based polyols were further characterised using FTIR analysis
(Figure 5). The representative spectrum for EPOo showed the presence of epoxide group at 820 to $860 \mathrm{~cm}^{-1}$ wavenumbers. The profiles of the FTIR spectra of POL-UC polyol and other polyols which were prepared using treated recycled K10 montmorillonite catalysts were similar. As expected, the palm-based polyol was characterised by a broad hydroxyl stretching peak at around $3500 \mathrm{~cm}^{-1}$. An absorption band at $3005 \mathrm{~cm}^{-1}$ and stretching peak at $1650 \mathrm{~cm}^{-1}$ which corresponded to alkene group $(\mathrm{C}=\mathrm{C})$ were not observed in all FTIR spectra of prepared palm-based polyols (Tran et al., 2005). No absorptions bands at around $820-860 \mathrm{~cm}^{-1}$, related to the epoxide ring, were observed, indicating the absence of epoxide groups. The ester group can be found at $1740 \mathrm{~cm}^{-1}$ for PB-Isob and other prepared palm-based polyol's FTIR spectra (Arniza et al., 2015; Norhayati et al., 2013).

The conversion of epoxide group and other properties of prepared palm-based polyols are shown in Table 3. All of the prepared palm-based polyols showed high percentage of OOC conversion, i.e., $\geq 90 \%$, which indicated that most of the epoxide rings have been opened. This clearly showed that all the catalysts had played their role in converting the

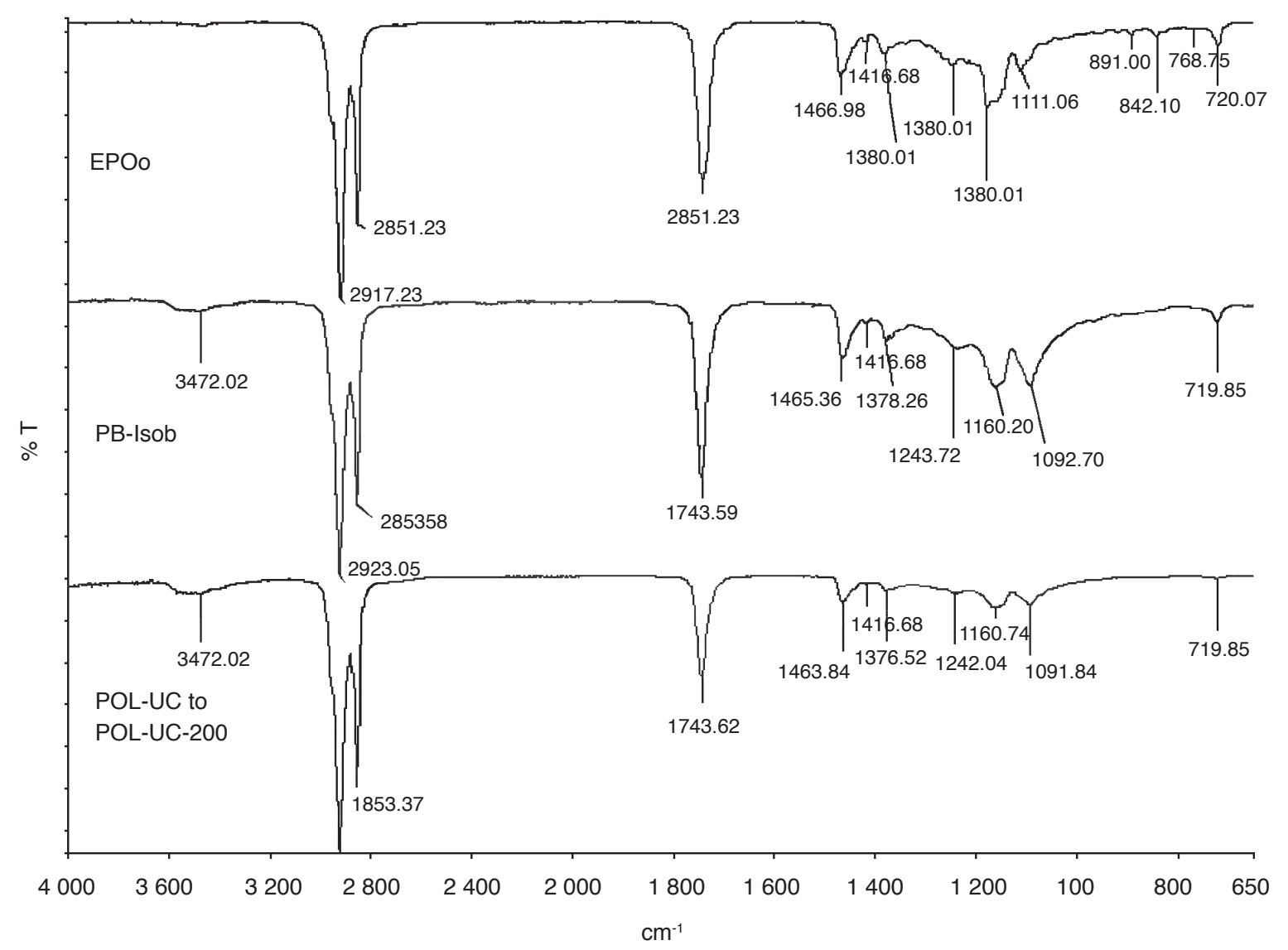

Note: PB-Isob - palm-based polyol prepared using fresh K10 catalyst and POL-UC to POL-UC-200 = palm-based polyols prepared using recycled K10 and treated recycled K10 catalysts. Peak assignments: epoxide group (820 to $\left.860 \mathrm{~cm}^{-1}\right)$, hydroxyl stretching $\left(3500 \mathrm{~cm}^{-1}\right)$ and ester group $\left(1740 \mathrm{~cm}^{-1}\right)$.

Figure 5. Fourier transform infared (FTIR) spectra of epoxidised refined, bleached and deodourised palm olein (EPOo), PB-Isob and other prepared palm-based polyols (POL-UC to POL-UC-200). 
TABLE 3. PROPERTIES OF THE PREPARED PALM-BASED POLYOLS USING DIFFERENT FORMS OF K10 CATALYSTS

\begin{tabular}{|c|c|c|c|c|c|c|c|}
\hline Properties & PB-Isob & POL-UC & POL-UC-W & POL-UC-50 & POL-UC-100 & POL-UC-150 & POL-UC-200 \\
\hline $\begin{array}{l}\text { Conversion of epoxide } \\
\text { group }(\%)\end{array}$ & 99 & 97 & 98 & 98 & 98 & 97 & 90 \\
\hline Moisture content, $(\%)$ & 0.05 & 0.04 & 0.04 & 0.05 & 0.05 & 0.05 & 0.05 \\
\hline $\begin{array}{l}\text { Iodine value, IV } \\
\left(\mathrm{g} \mathrm{I}_{2} 100 \mathrm{~g}^{-1}\right)\end{array}$ & $16.0 \pm 0.1$ & $13.0 \pm 0.2$ & $12.6 \pm 0.2$ & $13.0 \pm 0.2$ & $14.6 \pm 0.2$ & $14.7 \pm 0.2$ & $10.2 \pm 0.1$ \\
\hline $\begin{array}{l}\text { Acid value, } \mathrm{AV} \\
(\mathrm{mg} \mathrm{KOH} \mathrm{g-1})\end{array}$ & $1.0 \pm 0.1$ & $2.0 \pm 0.1$ & $1.1 \pm 0.1$ & $1.3 \pm 0.2$ & $1.2 \pm 0.2$ & $1.7 \pm 0.2$ & $0.8 \pm 0.1$ \\
\hline $\begin{array}{l}\text { Hydroxyl value, OHV } \\
\left(\mathrm{mg} \mathrm{KOH} \mathrm{g}^{-1}\right)\end{array}$ & $88.6 \pm 0.4$ & $79.2 \pm 0.5$ & $84.0 \pm 0.3$ & $86.8 \pm 0.2$ & $80.8 \pm 0.2$ & $78.2 \pm 0.2$ & $62.8 \pm 0.2$ \\
\hline Viscosity, mPa.s@ 25ํㅡ & 465.9 & 635.8 & 626.1 & 621.2 & 873.6 & 728.0 & 538.7 \\
\hline Colour Lovibond & $\begin{array}{l}0.9 \mathrm{R} \\
5.0 \mathrm{Y}\end{array}$ & $\begin{array}{l}4.4 \mathrm{R} \\
20.0 \mathrm{Y}\end{array}$ & $2.5 \mathrm{R} 20.0 \mathrm{Y}$ & 2.4R 10.0Y & 2.0R $10.0 \mathrm{Y}$ & 11.0R 12.0Y & $\begin{array}{l}\text { 20.0R 20.0Y } \\
13.0 \mathrm{~B}\end{array}$ \\
\hline $\begin{array}{l}\text { Weight average } \\
\text { molecular weight, } \\
\mathrm{M}_{\mathrm{w}} \text { (Dalton) }\end{array}$ & $1500-1600$ & $1700-1800$ & $1900-2000$ & $1400-1500$ & $1600-1700$ & $1200-1300$ & $1600-1700$ \\
\hline Polydispersity index, PDI & 1.4 & 1.5 & 1.6 & 1.4 & 1.5 & 1.2 & 1.5 \\
\hline
\end{tabular}

epoxide groups to hydroxyl groups, even though some of the reaction took longer time to complete.

As shown in Table 3, the moisture contents of all the prepared palm-based polyols were less than $0.05 \%$. The IV of the prepared palm-based polyols were in the range of 10.0 to $16.0 \mathrm{~g} \mathrm{I}_{2} 100 \mathrm{~g}^{-1}$. The IV content indicates the alkene group content in the polyol. Usually, the alkene group in the polyol is higher than the EPOo (Norhayati et al., 2013). This situation occurred due to elimination side reaction during the alcoholysis reaction. The intramolecular elimination reaction may also have occurred when the polyol was heated at high temperature during distillation or drying process (Daley and Daley, 2005).

The AV and OHV of all the prepared palmbased polyols were in the range of 0.8 to $2.0 \mathrm{mg}$ $\mathrm{KOH} \mathrm{g}{ }^{-1}$ and 63.0 to $88.0 \mathrm{mg} \mathrm{KOH} \mathrm{g}^{-1}$, respectively. The free fatty acid content present in the polyol was measured by AV analysis. Based on the obtained results, the prepared palm-based polyols gave a low $\mathrm{AV}$ content, i.e., less than $2.0 \mathrm{mg} \mathrm{KOH} \mathrm{g}^{-1}$ except for POL-UC polyol. The low AV content in the polyol is partially due to the method applied in preparing the polyol, where washing step or neutralisation process was not required in this study. Therefore, the tendency for hydrolysis to occur was less. It is known that the AV will increase when hydrolysis takes place during the neutralisation process. Even so, the $\mathrm{AV}$ of the prepared palm-based polyols showed a little increment value as compared to AV of EPOo. This might be due to autocatalytic hydrolysis, when free fatty acid initially present in the EPOo act as a catalyst to enhance subsequent formation of other free fatty acid (Lincon and Jacobsberg, 1965; Chooi et al., 2006). The trace of polyol in the UC catalyst might contribute to the increased of AV content in POL-UC polyol.

$\mathrm{OHV}$ is a measurement of the reactive hydroxyl group in polyol. The OHV of polyol depends on the types of epoxidised oil and alcohol used in the alcoholysis reaction. The epoxidised oil which contains high epoxide ring content will lead to the formation of polyol with high OHV. The alcohol used will also contribute to the OHV content in the polyol. For example, diol will contribute to the formation of two hydroxyl groups for each opened epoxide ring. The palm-based polyols produced in this study had lower OHV than those calculated theoretically from the idealised structure of palm-based polyol (Figure 2), i.e., $108.1 \mathrm{mg} \mathrm{KOH} \mathrm{g}^{-1}$. Based on theoretical OHV, $3.2 \%$ of $\mathrm{OOC}$ in the EPOo would produce $\mathrm{OHV}$ of $98.83 \mathrm{mg} \mathrm{KOH} \mathrm{g}^{-1}$ in the prepared palm-based polyols. However, the conversions of epoxide group were not $100 \%$ and this contributed to lower OHV as tabulated in Table 3. Furthermore, the epoxide group was not totally converted to hydroxyl group, evident by the increase of IV in palm-based polyol which might be caused by the elimination reaction.

It was observed that the hydroxyl value of palm-based polyols reduced as the temperature of the catalyst treatment (heating) increased from $50^{\circ} \mathrm{C}$ to $200^{\circ} \mathrm{C}$. The viscosities of all palm-based polyols were less than $1000 \mathrm{mPa} . \mathrm{s}$ at $25^{\circ} \mathrm{C}$. High viscosity might be attributable to side reactions such as polymerisation or cross-linking that occurred during the alcoholysis reaction which was not detected in this study. According to Petrovic et al., (2002), the excess of alcohol present in the reaction was important to prevent polymerisation, which can 
cause branching in the polyol. The excess isobutanol used in this study will prevent the polymerisation reaction as mentioned above. The colour of the prepared palm-based polyols is shown in Table 3. It was observed that the colour of the catalyst used in the alcoholysis had affected the colour of the prepared palm-based polyol. As the temperature of heat treatment was increased above $100^{\circ} \mathrm{C}$, the colour of the catalyst became darker and caused the dark colour of the polyol.

The ${ }^{1} \mathrm{H}$ and ${ }^{13} \mathrm{C}$ NMR were used to confirm the chemical structure of the palm-based polyol. All the palm-based polyols possessed the same ${ }^{1} \mathrm{H}$ and ${ }^{13} \mathrm{C}$ NMR spectra. Referring to ${ }^{1} \mathrm{H}$ NMR spectrum of prepared palm-based polyols (Figure 6), the epoxide ring-opening reaction with isobutanol in

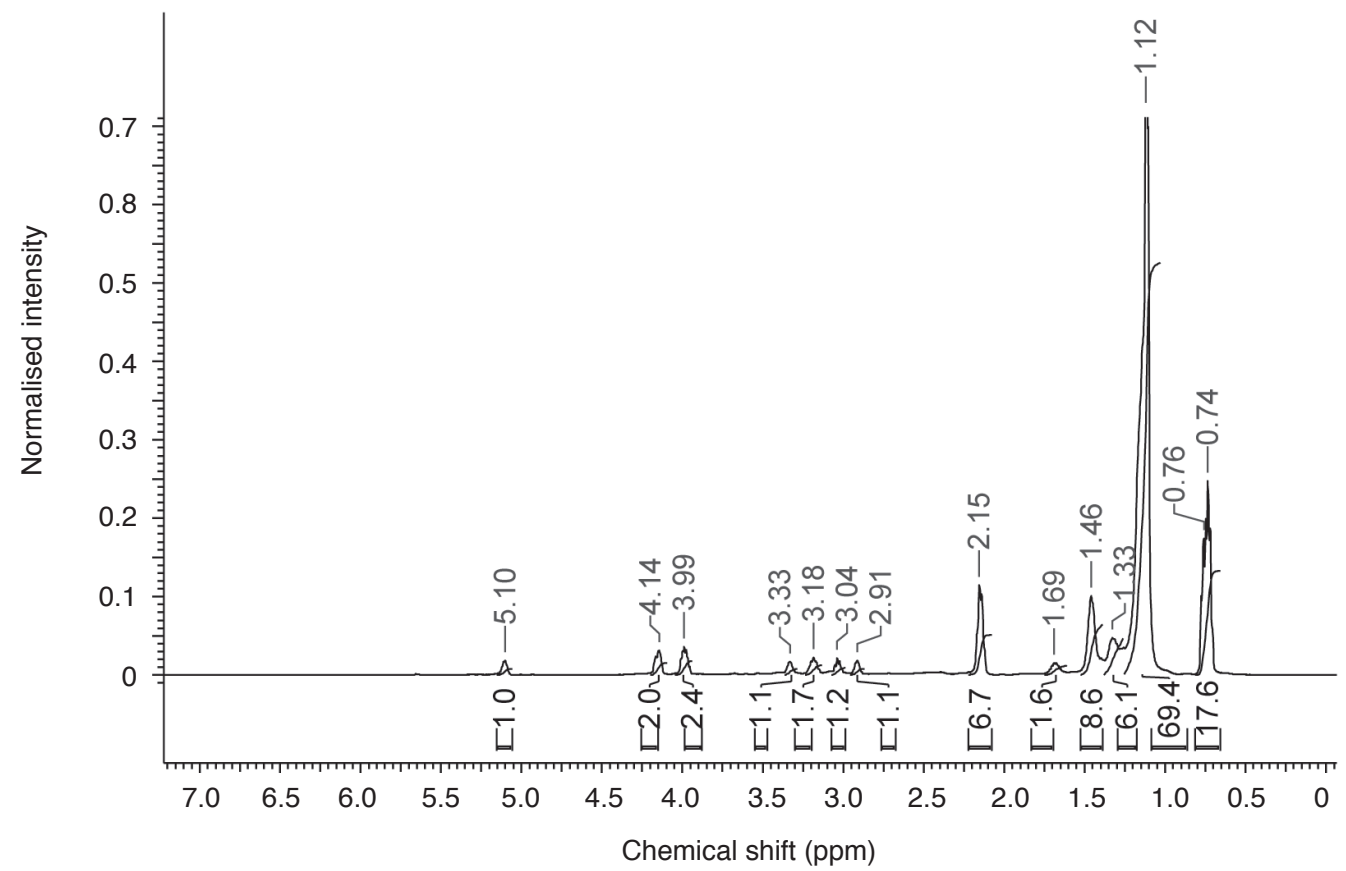

Figure 6. The ${ }^{1} \mathrm{H}$ NMR spectrum of prepared palm-based polyol. Peak assignments: $\delta 5.10(\mathrm{~s}, \mathrm{H}, \mathrm{CHO}), 4.14-3.97\left(m, 4 \mathrm{H}, \mathrm{CH}_{2} \mathrm{O}\right), 3.32(m, \mathrm{H}$, $\mathrm{CHOH}), 3.19-3.02\left(\mathrm{~m}, 2 \mathrm{H}, \mathrm{CH}_{2} \mathrm{O}\right), 2.91(\mathrm{~m}, \mathrm{H}, \mathrm{CHO}), 2.16-2.13\left(\mathrm{t}, \mathrm{J}=7.5 \mathrm{~Hz}, 6 \mathrm{H}, \mathrm{CH}_{2} \mathrm{COOR}\right), 1.70-1.65\left[\mathrm{~m}, 1 \mathrm{H}, \mathrm{CH}\left(\mathrm{CH}_{3}\right)_{2} \cdot\right], 1.50-1.42(\mathrm{~m}, 6 \mathrm{H}$, $\left.\mathrm{CH}_{2} \mathrm{CH}_{2} \mathrm{COOR}\right), 1.32-1.10\left(m, 70 \mathrm{H}, \mathrm{CH}_{2}\right), 0.78-0.71\left(m, 15 \mathrm{H}, \mathrm{CH}_{3}\right)$.

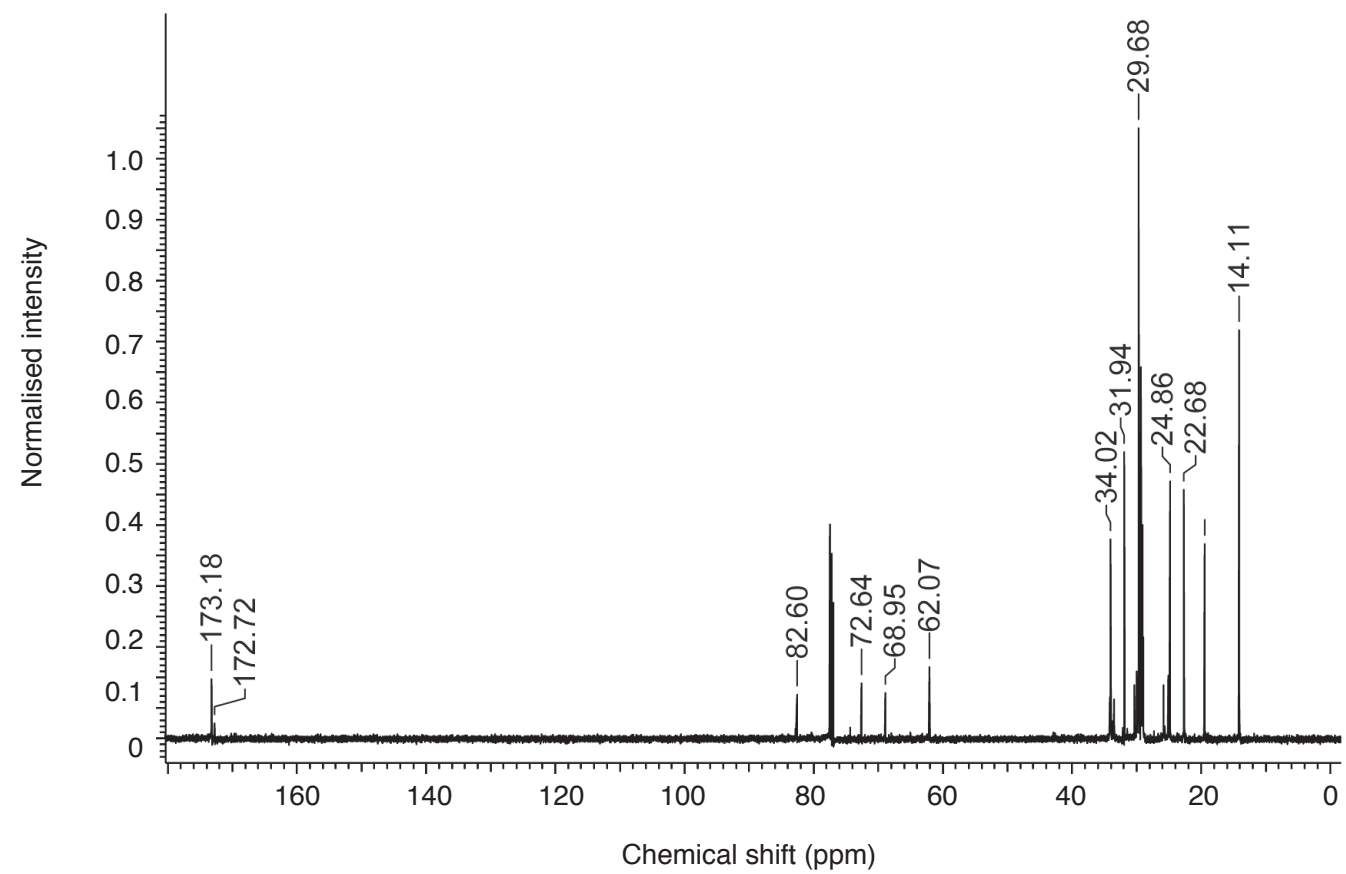

Figure 7. The ${ }^{13} \mathrm{C}$ NMR spectrum of prepared palm-based polyol. Peak assignments: $\delta 173.0-172.5(\mathrm{ROC}=\mathrm{O}), 82.4(\mathrm{COH}), 77.2(-\mathrm{CO}-), 72.4(\mathrm{COH})$, $68.8(\mathrm{HCO}), 61.8\left(\mathrm{H}_{2} \mathrm{C}-\mathrm{O}\right), 33.9\left(\mathrm{H}_{2} \mathrm{CC}=\mathrm{O}\right), 31.7-28.9\left(\mathrm{CH}_{2} \mathrm{CH}_{2}\right), 24.6\left(\mathrm{O}=\mathrm{CCH}_{2} \mathrm{CH}_{2}\right), 22.5\left(\mathrm{CH}_{2} \mathrm{CH}_{3}\right), 19.2\left(\mathrm{CHCH}_{3}\right), 13.9\left(\mathrm{CH}_{2} \mathrm{CH}_{3}\right)$. 

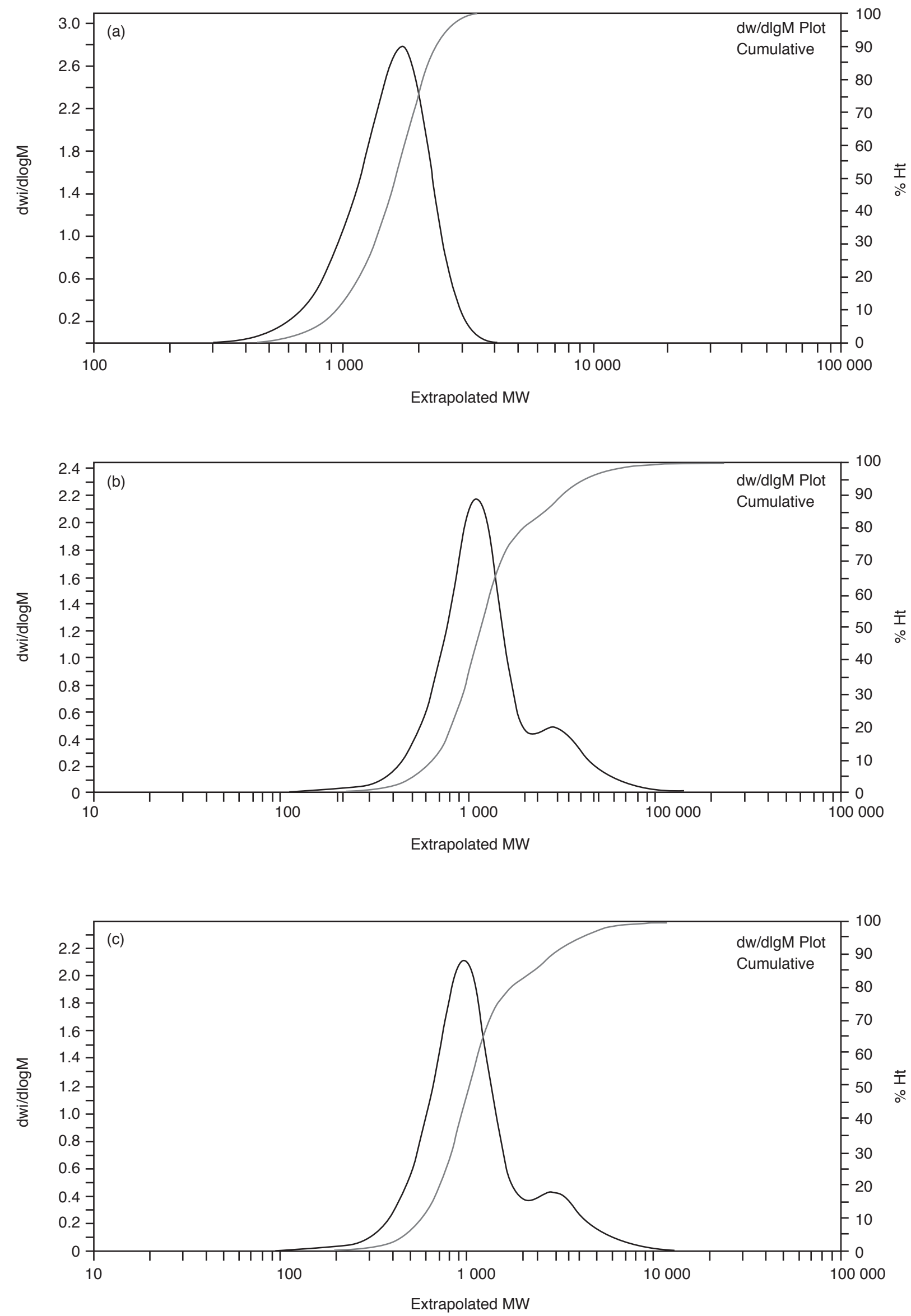

Figure 8. Gel permeation chromatography (GPC) chromatograms of (a) epoxidised refined, bleached and deodourised palm olein (EPOo), (b)PB-Isob and (c) POL-UC. 
the presence of K10 montmorillonite catalyst was successful due to the absence of peaks associated with epoxide group at $\delta 2.8-3.0 \mathrm{ppm}$. On the other hand, a peak that corresponded with the methine proton of isobutanol was observed at $\delta 1.65-1.70 \mathrm{ppm}$. This peak indicated that isobutanol successfully ring-opened the epoxide group to form ether functionality. Furthermore, peaks associated with ether and hydroxyl groups can be seen at $\delta 2.9-3.2$ ppm of the ${ }^{1} \mathrm{H}$ NMR spectrum. In addition, the methyl groups of isobutanol moiety were observed at $\delta 0.75 \mathrm{ppm}$ of the spectrum and was evident that the isobutanol moiety is part of the polyol's molecular structure. The analysis of ${ }^{1} \mathrm{H}$ NMR was supported by ${ }^{13} \mathrm{C}$ NMR spectrum (Figure 7) that showed carbon peaks associated with the methyl group of isobutanol at $\delta 19.2 \mathrm{ppm}$, and with hydroxyl and ether groups at $\delta$ 72.4-82.4 ppm, which were generated from the epoxide ring opening reaction with isobutanol. The existence of the alkene group was not observed in NMR spectra of palm-based polyols, consistent with FTIR analysis.

The GPC chromatograms and weight average molecular weight of polyols are shown in Figure 8 and Table 3, respectively. The weight average molecular weight of prepared palm-based polyols were within the range of 1200 to 2000 Daltons with their polydispersity indices between 1.2 and 1.6. It was observed that GPC chromatogram of EPOo showed a monomodal pattern. Meanwhile, GPC chromatograms of PB-Isob polyol and other prepared palm-based polyols showed a monomodal with a shoulder patterns. The GPC curve for POL-UC is similar to the curve of other prepared palm-based polyols (POL-UC-W to POL-UC-200). The GPC curve of the prepared palm-based polyols showed a dominant peak at molecular weight region of 200 to 2000 Daltons. Meanwhile, a shoulder peak was detected at molecular weight region of 2000 to 10 000 Daltons which might be attributed to oligomers generated by thermal polymerisation. Thermal polymerisation could occur during alcoholysis, distillation and drying process (Chang and Lu, 2012).

\section{CONCLUSION}

The performance of recycled K10 montmorillonite catalyst (untreated or treated at the selected temperature) in the alcoholysis of EPOo with isobutanol have been evaluated. Results showed that the acid sites content in the catalyst plays an important role in accelerating the alcoholysis reaction. At $60^{\circ} \mathrm{C}$ reaction temperature, all recycled and treated catalysts showed good catalysing activity even though some of them took a longer time to complete the reaction. The best heat treatment temperature of the catalyst was $100^{\circ} \mathrm{C}$ which exposed more acid sites content in the catalyst leading to the faster alcoholysis reaction. It can be concluded that K10 montmorillonite catalyst could be recycled in alcoholysis reaction of EPOo with isobutanol to produce high yield palm-based polyol of similar quality when compared to using fresh catalyst. An economic feasibility study may be needed to determine the optimum number of times the catalyst can be recycled in order to reduce the overall cost of polyol production.

\section{ACKNOWLEDGEMENT}

The authors would like to thank the DirectorGeneral of MPOB for permission to publish this article. Special thanks to Polimer and Composite Group of Advance Oleochemicals Technology Division, MPOB for technical support.

\section{REFERENCES}

ABRAHAM, T W (2012). Chapter II: Advances in the use of $\mathrm{BiOH} \circledast$ polyols in polyurethane. Biobased Monomers, Polymers and Materials (Smith, $\mathrm{P}$ et al. eds.). ACS Symposium Series; American Chemical Society; Washington, DC. p. 165-181.

ANG, K P; LEE, C S; CHENG, S F and CHUAH, C H (2014). Polyurethane wood adhesive from palm-based polyester polyol. J. Adhesion Science and Technology, 28(11): 1020-1033.

AOCS (2007). Section C: Sampling and analysis of commercial fats and oils (reapproved 1997). Official Methods and Recommended Practices of the AOCS. Fifth edition.

ARNIZA, M Z; HOONG, S S; IDRIS, Z; YEONG, S K; HASSAN, H A; DIN, A K and CHOO, Y M (2015). Synthesis of transesterified palm olein-based polyol and rigid polyurethane from this polyol. J. Amer. Oil Chem. Soc., 92: 243-255.

ARGYROPOULOS, J; POPA, P; SPILMAN, G; BHATTACHARJEE, D and KOONLE, W (2009). Seed oil based polyester polyols for coating. J. Coat. Technol. Res., 6(4): 501-508.

BADRI, K H; AHMAD, S H and ZAKARIA, S (2001). Production of a high-functionality RBD palm kernel oil-based polyester polyol. J. Applied Polymer Science, 81: 384-389.

BALLANTINE, J A (1995). Reactions assisted by clays and other lamellar solids - A survey. Chemiform., 26(28). 
CHANG, C and LU, K (2012). Natural castor oil based 2-package waterborne polyurethane wood coatings. Progress in Organic Coating, 75: 435-443.

CHOOI, S Y; KOH, H F and WREN, W G (2006). Autocatalytic hydrolysis and autoxidation of crude palm oil under various constant humidities. J. Oil Palm Res. Vol. 18: 278-287.

DALEY, R F and DALEY, S J (2005). Elimination reaction. Organic Chemistry. www.ochem4free.com, accessed on 7 February 2017. p. 656-702

HAZIMAH, A H; TUAN NOOR MAZNEE, T I; MOHD NORHISHAM, S; HOONG, S S; OOI, T L; SALMIAH, A; KOSHEELA DEVI, $\mathrm{P} P$ and CHEONG, M Y (2011). Process to produce polyols. US patent 7,932,409 B2.

KAUR, N and KISHORE, D (2012). Montmorillonite: An efficient, heterogeneous and green catalyst for organic synthesis. J. Chemical and Pharmaceutical Research, 4(2): 991-1015.

LI, F; HANSON, M V and LAROCK, R C (2001). Soybean oil-divinyl benzene thermosetting polymers: Synthesis, structure, properties and their relationships. Polymer, 42: 1567-1579.

LI, Y; LUO, X and HU, S (2015). Polyols and polyurethanes from vegetable oils and their derivatives. SpringerBriefs in Green Chemistry for Sustainibility. DOI 10.1007/978-3-319-21539-6_2.

LIN, B; YANG, L; DAI, H and YI, A (2008). Kinetic studies on oxirane cleavage of epoxidized soybean oil by methanol and characterization of polyols. $J$. Amer. Oil Chem. Soc., 85: 113-117.

LINCON, M and JACOBSBERG, B (1965). Research on palm oil in Belgium and the Congo. The Oil Palm. London. Trop. Prod. Inst. p. 85-95.

LOZADA, Z; SUPPES, G J; TU, Y C and HSIEHM, F H (2009). Soy-based polyols from oxirane ring opening by alcoholysis reaction. J. Applied Polymer Science, 113: 2552-2560.

MADEJOVÁ, J (2003). FT-IR techniques in clay mineral studies. Vibrational Spectroscopy, 31(1): 1-10.

NAGENDRAPPA， G (2002). Organic synthesis using clay catalysts. Resonance: J. Science Education, 7(1): 64-77.

NARINE, S S; YUE, J and KONG, Y (2007). Production of polyols from canola oil and their chemical identification and physical properties. $J$. Amer. Oil Chem. Soc., 84: 173-179.
NORHAYATI, M N; TUAN NOOR MAZNEE, T I; YEONG, S K and HAZIMAH, A H (2013). Synthesis of palm-based polyols: Effect of K10 montmorillonite catalyst. J. Oil Palm Res. Vol. 25(1): 92-99.

NORHAYATI, M N; TUAN NOOR MAZNEE, T I; HOONG, S S; NURUL 'AIN, H; SRIHANUM, A; KOSHEELA DEVI, P P; MOHD NORHISHAM, S; YEONG, S K and HAZIMAH, A H (2016a). Reproducibility of palm-based polyols production. J. Oil Palm Res. Vol. 28(1): 114-120.

NORHAYATI, M N, AISA, S; VAHID, S; IBRAHIM, S; TUAN NOOR MAZNEE, T I; MOHD AZMIL, M N; YEONG, S K and HAZIMAH, A H (2016b). Comparison of adipic versus renewable azelaic acid polyester polyols as building blocks in soft thermoplastic polyurethanes, J. Amer. Oil Chem. Soc., 93: 1529-1540. DOI: 10.1007 / s11746-016-2903-9.

PETROVIC, Z; JAVNI, I; GUO, A and ZHANG, W (2002). Method of making natural oil-based polyols and polyurethane thereform. US patent 6433121 B1.

RIOS, L A; WECKES, P P; SCHUTER, H; HAUSMANN, $\mathrm{H}$ and HÖLDERICH, W F (2003). Modification and characterization of aluminosilicates used for nucleophilic addition of alcohols to epoxidized oils. Applied Catalysis A: General, 253: 487-497.

RIOS, L A; WECKES, P P; SCHUTER, $\mathrm{H}$ and HÖLDERICH, W F (2005). Resin catalysed alcoholysis of epoxidized fatty esters: Effect of the alcohol and the resin structures. Applied Catalysis A: General, 284: 155-161.

SEIGFRIED, K F P; RUTH, G; HANS-PETER, N and ECKHARD, W (2002). Alcoholysis of triacyglycerols by heterogeneous catalysis. Eur. J. Lipid. Sci. Technol., 104: 324-330.

TAY, B Y P and NURUL, A H (2012). Conventional gel permeation chromatography vs gel permeation chromatography with combined detectors for analyses of palm oil-based polyols. J. Oil Palm Res. Vol. 24: 1421-1429.

TRAN, P; GRAIVER, D and NARAYAN, R (2005). Ozone-mediated polyol synthesis from soybean oil. J. Amer. Oil Chem. Soc. 82(9): 653-659.

TONG, D S; XIA, X; LUO, X P; WU, L M; LIN, C X; YU, W H; ZHOU, C H and ZHONG, Z K (2013). Catalytic hydrolysis of cellulose to reducing sugar over acid-activated montmorillonite catalysts. Applied Clay Science, 74: 147-153.

ZLATANIC, A; PETROVIC, Z S and DUSEK, K (2002). Structure and properties of triolein-based polyurethane networks. Biomacromolecules, 3: 10481056. 